\title{
BIG FIVE PERSONALITY AND SOCIAL DISCRIMINATION AMONG UNIVERSITY STUDENTS
}

\author{
Ridwana
}

Ph.D Scholar

Central University of Kashmir

ridwanmehraj@gmail.com

DOI $10.26821 /$ IJSRC.8.9.2020.8903>

\begin{abstract}
India is known for its ethnic and cultural diversity. Ethnicity and class has considerable impact on the development of personality, emotional intelligence, adjustment, pro-social behaviour, mental health of an individual. Caste determines ones status and position in the society. It has grave influence on person's life in total and relationships with others around. Personality plays an important role in one's life and is the predictor of one's success. Studies have shown that there is correlation between personality and academic achievement, career maturity, career preferences, emotional intelligence etc. Big Five Personality Model is considered as the well-researched conceptualized model, consisting of both positive and negative traits. The aim of the present research paper is to determine the impact of social discrimination on Big Five Personality among university students. Sample used for the study consisted of 100 (50 Open-merit \& 50 SC) PG students selected from two Universities (Kashmir University, and Jammu University), through stratified random technique. Tool used for the purpose of data collection was Costa and McCrae's Big Five Personality Questionnaire (NEO- FFI- 3). Data was analysed by using mean and t-test. On Neuroticism, Openness, and Conscientiousness factors of Big Five Personality, insignificant difference were found between Open-merit and Scheduled caste university students. The significant difference was found between Open-merit and SC students on Extraversion and Agreeableness factors of Big Five Personality.
\end{abstract}

Key Words; Social Discrimination, Big Five Personality Model, Scheduled caste, Open- merit, University education.

\section{INTRODUCTION}

University education is considered as the final stage of learning. It begins immediately after completion of Higher Secondary or college education. At this stage of higher learning, students are ready to enter the real world with an aptitude to cope any sort of problems that may come up. It is at this period, the personality attains final shape or traits get internalized. In Indian society, the process of Social stratification creates severe impediments in development of personality. This division is on the basis of occupation or birth, which is in Indian society since from decades and still continues despite the efforts made by Government of India. Studies have shown that, the caste or class system impacts an individual's overall progress in terms of academic achievement, Mental Health, values, adjustments etc. It even persists as menace at university level, where the students face discrimination in the classroom and outside, through classmates, administrators, and from teachers too. 
Open-Merit (General): This category includes those students who are not falling under any reservations. They are also called as General or Unreserved category.

Scheduled caste (SC): This category includes those candidates who are occupying the lowest status in Indian Society like Dalits (Untouchables).

Personality is considered as configuration of thoughts, behavior, emotions, that build up in an individual as a result of interaction with the environment. It is considered as most debatable concept in psychology. The accurate definition of personality is hard to present. However, the psychologists, for whom the concept of personality is of utmost importance, cannot escape the necessity of attempting a precise statement about personality. According to Allport (1961) "personality is the dynamic organization within the individual of those psychophysical systems that determine his characteristic behavior and thought". Personality is manifested through speech, the way person response to the stimuli, or people's aptitude to handle with any kind of problem, and the potential to carry out elusive thoughts. How the person is consciously, subconsciously and unconsciously, accounts as his personality. Personality factors are considered as better predictors of Adjustment, Success in job, Intelligence, Emotional intelligence, Sense of Self, etc. various studies have shown that social discrimination have negative effect on personality development. Students belonging to the lower caste or class are found to be shy, and introvert which in turn impact their social behavior. They prefer to be isolated from the society, as they think they are not as equal members as that of people of higher class and caste. The person who scores high on Extroversion and Agreeableness are having sound knowledge about the types of career, as they don't hesitate in getting knowledge from people around (Obi Monica Chinyere 2017). Study of ( Barrick \& Mount 1991) supported that Big Five model can be used for analyzing one's personality and also showed that Conscientiousness factor as determinant of Intrinsic success and Extrinsic success.

\section{Big Five Personality Model}

Psychologists considered this model as the universally accepted theory. They believe that personality of an individual can be boiled down to five core factors which are- Openness, Conscientiousness, Agreeableness, Extroversion and Neuroticism (OCEAN).

\section{Openness (O):}

This factor of personality is defined in terms of degree, the person is open to the new things or variety of stimuli. The person with this factor are characterized with curiosity, better sense of beauty, are conscious to their inner feelings and are independent in decision making process.

\section{Extraversion (E)}

This factor is defined in terms of outgoing and fun loving. The person possessing this factor experience positive feelings about themselves and that of others. They like to be surrounded by people.

\section{Agreeableness (A)}

People who are high on this factor are found to be pro-social, selfless, peace loving and are always ready to help people.

\section{Conscientiousness (C)}

This factor has been described in terms of desire control, social conformity, organized, dutiful, competent, devoted, dependable, responsible, punctual and hardworking. Those persons who have conscientiousness have fewer goals and exhibit self-discipline with focus.

\section{Neuroticism (N)}

It is defined as the tendency to experience stress. The person who scored high on this factor tends to be anxious, pessimistic, tense and worrying.

\section{Statement of the problem}

"Big Five Personality and Social Discrimination among university students" 


\section{Objectives}

1. To study the personality among university students.

2. To study the personality among Open-merit university students.

3. To study the personality among scheduled caste university students.

4. To compare Open-merit and SC university students on various factors of Big Five Personality model.

\section{Hypothesis}

1) There is no significant difference between Open-merit and SC university students on Big Five Personality model

\section{METHODOLOGY}

\section{OPERATIONAL DEFINITION:}

For the present study, personality is operationally defined as the scores, which the investigator has got after administrating the Costa and McCrae's Big Five Personality inventory (NEO-FFI-3).

\section{SAMPLE:}

The present study was carried on 100 (50 Open-merit \& 50SC) university students, selected from two universities through stratified random sampling technique.

\section{Tool:}

Data was collected with the help of Costa and McCrae's scale of Big Five Personality. The questionnaire comprises of five factors-Neuroticism, Extroversion, Openness, Agreeableness and Conscientiousness.

\section{Statistical Analyses and Interpretation}

Raw data was subjected to the Mean and t-test statistical treatment:

Table is showing mean difference among the university students on Big Five personality model $(\mathrm{N}=100)$.

\begin{tabular}{|l|c|c|c|c|c|}
\hline FACTORS & N & Minimum & Maximum & Mean & Std. Deviation \\
\hline NEUROTICISM & 100 & 9 & 44 & 25.05 & 5.684 \\
\hline EXTRAVERSION & 100 & 8 & 38 & 27.08 & 4.758 \\
\hline OPENNESS & 100 & 18 & 39 & 27.91 & 4.513 \\
\hline AGREEABLENESS & 100 & 11 & 40 & 26.88 & 5.645 \\
\hline CONSCIENTIOUSNESS & 100 & 14 & 41 & 29.47 & 5.064 \\
\hline
\end{tabular}


Volume 8 Issue 10 October 2020

The perusal of above table provides the mean description among the university students on five factors of Big Five Personality model. It is clear through the table that university students achieved highest mean on 'Conscientiousness' factor. Further, it is clear from the table that lowest mean is attained by the students is on 'Neuroticism' factor of Big Five Personality model.

Table showing mean difference between Scheduled caste and Open- merit students on 'Neuroticism' factor of personality.

\begin{tabular}{|l|l|l|l|l|l|r|}
\hline Factor & category & N & Mean & $\begin{array}{l}\text { Std. } \\
\text { Deviation }\end{array}$ & t-value & p-value \\
\hline \multirow{2}{*}{ NEOROTICISM } & SC & 50 & 25.62 & 5.119 & & \\
\cline { 2 - 7 } & Open-merit & 50 & 24.48 & 6.198 & 1.003 & .318 \\
\hline
\end{tabular}

The above table reflects mean difference between the scheduled caste and open-merit university students on Neuroticism factor of personality. The table reveals that there is insignificant difference between these two categories of university students on Neuroticism factor. On the basis of mean score, Scheduled caste students scored high than Open- merit.

Table showing mean difference between SC and Open- merit students on 'Extraversion' factor of personality.

\begin{tabular}{|l|l|l|l|c|c|c|}
\hline \multirow{2}{*}{ Factor } & category & $\mathbf{N}$ & Mean & $\begin{array}{c}\text { Std. } \\
\text { Deviation }\end{array}$ & t-value & p-value \\
\hline \multirow{2}{*}{ EXTRAVERSION } & SC & 50 & 26.64 & 4.222 & \multirow{2}{*}{2.18} & \multirow{2}{*}{0.05} \\
\cline { 2 - 5 } & Open-merit & 50 & 28.72 & 5.246 & \\
\hline
\end{tabular}

The above table reveals the mean difference between scheduled caste and Open- merit students on Extraversion factor of personality. The table depicts that there is significant difference between these two groups at 0.05 level. Further the mean score (28.72) of Open- merit is decidedly better than the mean score (26.64) of scheduled caste university students.

Table showing mean difference between SC and Open- merit students on 'Openness' factor of personality.

\begin{tabular}{|l|l|c|c|c|c|c|}
\hline \multirow{2}{*}{ Factor } & category & $\mathbf{N}$ & Mean & $\begin{array}{c}\text { Std. } \\
\text { Deviation }\end{array}$ & t-value & p-value \\
\hline \multirow{2}{*}{ OPENNESS } & SC & 50 & 27.10 & 4.786 & 1.816 & .072 \\
\cline { 2 - 7 } & Open-merit & 50 & 28.72 & 4.111 & 1.672 \\
\hline
\end{tabular}

From the above table, it is clear that there is insignificant difference between general and scheduled caste students on Openness factor of personality. Though the mean difference favored Open- merit but the difference failed to arrive any level of significance. 
Table showing mean difference between Scheduled caste and Open- merit students on 'Agreeableness' factor of personality.

\begin{tabular}{|l|l|l|l|c|c|c|}
\hline Factor & category & $\mathbf{N}$ & Mean & $\begin{array}{c}\text { Std. } \\
\text { Deviation }\end{array}$ & t-value & p-value \\
\hline \multirow{2}{*}{ AGREEABLENESS } & SC & 50 & 25.36 & 4.818 & \multirow{2}{*}{2.783} & .006 \\
\cline { 2 - 5 } & Open-merit & 50 & 28.40 & 6.037 & \multirow{2}{*}{2.783} \\
\hline
\end{tabular}

On Agreeableness factor, the table reflects significant difference between Scheduled caste and Openmerit students at 0.01 level of significance. It is further clear that mean score (28.40) of Open- merit is high than the mean score (25.36) of scheduled caste students.

Table showing the mean difference between Scheduled caste and Open- merit students on 'Conscientiousness' factor of personality.

\begin{tabular}{|l|l|l|l|c|c|c|}
\hline \multirow{2}{*}{ Factor } & category & $\mathbf{N}$ & Mean & $\begin{array}{c}\text { Std. } \\
\text { Deviation }\end{array}$ & t-value & p-value \\
\hline \multirow{2}{*}{ CONSCIENTIOUSNESS } & SC & 50 & 29.04 & 5.245 & \multirow{2}{*}{0.848} & .399 \\
\cline { 2 - 7 } & Open-merit & 50 & 29.90 & 4.892 & 0.848 \\
\hline
\end{tabular}

The above table shows that there is insignificant difference, between scheduled caste and Open- merit on 'Conscientiousness' factor of personality. Despite the fact that mean score of scheduled caste student is more than the mean score of Open- merit students, but the difference failed to arrive any level of significance.

\section{DISCUSSION OF THE RESULTS}

Open- merit and scheduled caste university students were compared on the five factors of Big Five Personality model- Neuroticism, Extraversion, Openness, Agreeableness and Conscientiousness. It was found that both the groups were same on Neuroticism, Openness and Conscientiousness factors of personality.

On Agreeableness factor of personality, open- merit students found to be higher than their counterparts. The general category students are possessing pro social behavior. They like to be surrounded by people. They are quite helpful, supportive, cooperative and accommodating. The open- merit students are found to be outgoing, gregarious, assertive and live. They indulge themselves in any sort of discussions. The reason behind the shy nature of scheduled caste students is due to the attitude of people towards this marginalized section of society. They are considered as impure and their religious brothers keep distancing from them. Being literate, students belonging to higher caste in university hostels avoid sharing room with students of lower caste. This factor ruins their personality and they also even shun participating in any functions, held in the educational institutions.

\section{References}

Barrack, M.R., \& Mount, M.K. (1991).The Big Five Personality Dimensions in Job Performance, Personnel Psychology, (44), p- 1-26.

Chinyere, O.M. (2017). Relationship Between Personality Traits And Career Decision Making Self-Efficacy Among Male And Female Undergraduates In Malaysia, Faculty of Education University Teknologi Malaysia, Ph.D Thesis.Dr. Radhakrishnan commission report on higher education (2017). NMIMS Journal of Economics and Public Policy vol. II .

Costa PT, McCrae RR (1992). Revised NEO Personality Inventory (NEO-PI-R) and NEO Five-Factor Inventory (NEO-FFI) manual. Odessa, Florida: Psychological Assessment Resources. 